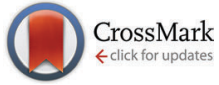

Cite this: J. Mater. Chem. C, 2015, 3, 7890

\title{
Bead-like structures and self-assembled monolayers from 2,6-dipyrazolylpyridines and their iron(II) complexes $\dagger$
}

\author{
Laurynas Pukenas, ${ }^{a}$ Florence Benn, ${ }^{a}$ Edmund Lovell, ${ }^{a}$ Amedeo Santoro, ${ }^{b}$ \\ Laurence J. Kershaw Cook, ${ }^{b}$ Malcolm A. Halcrow ${ }^{\star b}$ and Stephen D. Evans ${ }^{\star a}$
}

\begin{abstract}
Drop-casting acetone solutions of $\left[\mathrm{Fe}(\mathrm{bpp})_{2}\right]\left[\mathrm{BF}_{4}\right]_{2}$ (bpp $=2,6$-di[pyrazol-1-yl]pyridine) onto a HOPG surface affords unusual chain-of-beads nanostructures. The beads in each chain are similar in size, with diameters in the range of 2-6 nm and heights of up to $10 \AA$, which is consistent with them containing between 10-50 molecules of the compound. The beads can be classified into two types, which exhibit different conduction regimes by current-imaging tunnelling spectroscopy (CITS) which appear to correlate with their positions in the chains, and may correspond to molecules containing high-spin and low-spin iron centres. Similarly drop-cast films of the complex on a gold surface contain the intact $\left[\mathrm{Fe}(\mathrm{bpp})_{2}\right]\left[\mathrm{BF}_{4}\right]_{2}$ compound by XPS. 4-Mercapto-2,6-di[pyrazol-1-yl]pyridine undergoes substantial decomposition when deposited on gold, forming elemental sulfur, but 4-(N-thiomorpholinyl)-2,6-di[pyrazol-1-yl]pyridine successfully forms SAMs on a gold surface by XPS and ellipsometry.
\end{abstract}

Received 3rd May 2015 Accepted 26th May 2015 DOI: $10.1039 / c 5 t c 01233 c$

www.rsc.org/MaterialsC

\section{Introduction}

Spin-crossover compounds, which undergo a transition between electronic spin states under the influence of temperature, pressure or light, are a versatile form of molecular switch. ${ }^{1-5}$ They are molecular complexes or coordination polymers of first row transition ions with a $d^{4}-d^{7}$ electron count, and an intermediate ligand field that makes their high-spin and low-spin states close in energy. The phenomenon is common in iron(II), ${ }^{6}$ iron(III) ${ }^{7}$ and cobalt(II) ${ }^{8}$ chemistry, although examples containing other transition ions are also well known. The spin-crossover event in a solid material leads to concomitant changes to a number of its physical properties, including its magnetic moment, ${ }^{9}$ colour, ${ }^{9}$ electrical resistance ${ }^{10,11}$ and dielectric constant. ${ }^{12}$ It can also lead to unusual thermal expansion behaviour around the temperature of the transition. ${ }^{13}$

Much recent effort has been devoted to investigating spintransition compounds in nanoscale materials. ${ }^{14-16}$ Nanoparticle

\footnotetext{
${ }^{a}$ School of Physics and Astronomy, E. C. Stoner Building, University of Leeds, Leeds, LS2 9JT, UK. E-mail: s.d.evans@leeds.ac.uk; Fax: +44 113343 3900; Tel: +44 1133433852

${ }^{b}$ School of Chemistry, University of Leeds, Woodhouse Lane, Leeds, LS2 9JT, UK. E-mail: m.a.halcrow@leeds.ac.uk; Fax: +44 113343 6565; Tel: +44 1133436506 $\dagger$ Electronic supplementary information (ESI) available: Synthetic procedures and characterisation data for $\mathrm{L}^{2}, \mathrm{~L}^{3}$ and salts of $\left[\mathrm{Fe}\left(\mathrm{L}^{3}\right)_{2}\right]^{2+}$; experimental details, figures and tables for crystal structures of $\left[\mathrm{Fe}\left(\mathrm{L}^{3}\right)_{2}\right] \mathrm{X}_{2}\left(\mathrm{X}^{-}=\mathrm{BF}_{4}^{-}, \mathrm{ClO}_{4}{ }^{-}\right.$and $\mathrm{CF}_{3} \mathrm{SO}_{3}{ }^{-}$); additional STM images, XPS and ellipsometry data. CCDC 10587491058751. For ESI and crystallographic data in CIF or other electronic format see DOI: $10.1039 / \mathrm{c} 5 \mathrm{tc} 01233 \mathrm{c}$
}

preparations and films of $\geq 50 \mathrm{~nm}$ in diameter generally show comparable spin-state switching properties to the corresponding bulk materials. At smaller thicknesses the switching performance is influenced by inactive metal centres at the surface of the nanostructures. This usually leads to an attenuation of the switching performance as the size is reduced, although a recovery in switching cooperativity was recently detected in 2-3 nm particles which was attributed to the rigidity of the particle surface. $^{17}$

Most of these studies have been performed using coordination polymer materials, ${ }^{18}$ and the nanochemistry of molecular spin-crossover compounds is less advanced. Best studied is $\left[\mathrm{Fe}\left(\mathrm{H}_{2} \mathrm{Bpz}\right)_{2}(\mathrm{phen})\right](\mathrm{pz}=$ pyrazolyl, phen = 1,10-phenanthroline), which has been fabricated into homogeneous films on a number of surfaces by vacuum deposition, at thicknesses ranking from $10^{2} \mathrm{~nm}$ to sub-monolayer coverage. ${ }^{19-25}$ Isolated molecules of $\left[\mathrm{Fe}\left(\mathrm{H}_{2} \mathrm{Bpz}\right)_{2}\right.$ (phen)] on $\mathrm{Au}(111)$ can exist in either their high- or low-spin states by STM, but appear to be unable to switch between the two ${ }^{24,25}$ (in some cases, this could reflect partial decomposition of the molecules on the substrate ${ }^{22}$ ). In contrast monolayer, bilayer or multi-layer films can undergo the expected spin-state switching under a thermal, optical or charge stimulus, although the conditions leading to the onset of switching in the films have varied between studies. Functional, polycrystalline films and surface patterns of other molecular spin-crossover switches have also been produced by vacuum deposition, ${ }^{26-28}$ spin-coating, ${ }^{10,29}$ drop-casting ${ }^{30,31}$ and lithographic methods. ${ }^{32,33}$ In contrast, self-assembled monolayers (SAMs) of spin-crossover 


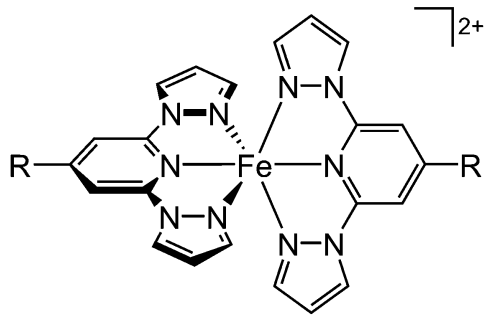<smiles>c1cc(-n2cccn2)nc(-n2cccn2)c1</smiles><smiles>Sc1cc(-n2cccn2)nc(-n2cccn2)c1</smiles><smiles>N#CSCc1cc(-n2cccn2)nc(-n2cccn2)c1</smiles><smiles>c1cnn(-c2cc(N3CCSCC3)cc(-n3cccn3)n2)c1</smiles>

Scheme 1 The structure of the $\left[\mathrm{Fe}(\mathrm{bpp})_{2}\right]^{2+}$ family of complexes, and the bpp ligand derivatives discussed in this work.

complexes have not yet been reported, although progress towards that end has been achieved using a different type of molecular spin-state switch. ${ }^{34}$

Much of our work has focussed on the $\left[\mathrm{Fe}(\mathrm{bpp})_{2}\right]^{2+}$ family of complexes, where bpp is 2,6-di(pyrazol-1-yl)pyridine or a derivative of it (Scheme 1). ${ }^{35}$ The synthetic flexibility of the bpp ligand allows a variety of substituents to be appended to the complex molecule, while retaining its spin-crossover functionality. ${ }^{35,36}$ Derivatives of $\left[\mathrm{Fe}(\mathrm{bpp})_{2}\right]^{2+}$ have been fabricated into surface nanostructures ${ }^{10,30,31,33}$ and single-molecule junctions. ${ }^{37}$ of particular note is a report from Grohmann et al., who dropcast $\left[\mathrm{Fe}\left(\mathrm{L}^{1}\right)_{2}\right]\left[\mathrm{BF}_{4}\right]_{2}$ onto HOPG. ${ }^{30}$ This afforded unusual "chainof-beads" structures on the graphite surface, each bead having a diameter of $2 \mathrm{~nm}$ by scanning-tunnelling microscopy (STM). That corresponds to a small cluster of molecules if the beads contain the intact complex. Individual beads gave different $I / V$ response curves by current imaging tunnelling spectroscopy (CITS), which were proposed to arise from molecules in their high- and low-spin states. Some beads were observed to switch between the two forms over a period of minutes, under a constant bias, in an apparently random manner. ${ }^{38}$ Comparable data from two salts of the unsubstituted analogue $\left[\mathrm{Fe}(\mathrm{bpp})_{2}\right]^{2+}$ were also briefly described by the same group. ${ }^{38}$

We report here two investigations of the surface chemistry of $\left[\mathrm{Fe}(\mathrm{bpp})_{2}\right]^{2+}$ derivatives. First is a study of drop-casting $\left[\mathrm{Fe}(\mathrm{bpp})_{2}\right]\left[\mathrm{BF}_{4}\right]_{2}{ }^{39}$ on HOPG, which has afforded comparable surface structures to those of $\left[\mathrm{Fe}\left(\mathrm{L}^{1}\right)_{2}\right]\left[\mathrm{BF}_{4}\right]_{2} \cdot{ }^{30}$ In addition to STM and CITS data, we also report the first XPS measurements that support the chemical composition of the drop-cast nanostructures. Second, is an investigation of SAMs formed from two bpp derivatives containing sulfur substituents, $\mathrm{L}^{240}$ and the new ligand $\mathrm{L}^{3}$.

\section{Results and discussion}

Acetone solutions of $\left[\mathrm{Fe}(\mathrm{bpp})_{2}\right]\left[\mathrm{BF}_{4}\right]_{2}{ }^{39}$ were drop-cast onto a freshly cleaved HOPG surface, and the resultant nanostructures were examined by STM. The drop-casting procedure was found to consistently lead to "chain of beads" structures on the graphite surface (Fig. 1). The chains were up to 1-2 $\mu \mathrm{m}$ in length, and while the bead structures in each chain were reasonably homogeneous, there were some differences between the beads in different chains. The diameters of beads in different sets varied between 2-6 nm, and their heights ranged from $4 \AA$ up to as much as $10 \AA$ (Fig. 1). Peak-to-peak separations of between $5 \mathrm{~nm}$ and $12 \mathrm{~nm}$ were evident in different chains, although beads were sometimes touching or sometimes well-separated in the chains depending on the bead size (Fig. 2).

Other recurring features in the deposited complexes include chains traversing across substrate step edges, and chains that change direction at distinct, consistent angles (ESI $\dagger$ ). However, different types of structure were observed at the ends of chains, including an abrupt termination of a chain associated with a sequence of HOPG step edges, and a more gradual petering out of the beads on an apparently featureless region of the surface (ESI $\dagger$ ). Although the beads superficially resemble moire patterns on the HOPG surface, ${ }^{41}$ the bead structures are clearly distinguishable from moiré patterns by STM and by CITS (see below), in images that contain both features (ESI $\dagger$ ).

Several different chains-of-beads were scanned using CITS at $290 \mathrm{~K}$ and $203 \mathrm{~K}$ where, based on the properties of the bulk complex, they would be expected to be in the high-spin and low-spin state respectively. ${ }^{39}$ In general, there is a marked difference between the spectroscopy of the beads and the substrate, with some beads being darker (type I) and some brighter in current (type II) ${ }^{38}$ The difference between type I and type II beads is also evident in the $I / V$ response, since type II beads exhibit a larger current than type I (Fig. 3). At room temperature this difference was only evident at larger biases of $> \pm 0.15 \mathrm{~V}$, but improved sensitivity between the beads at lower biases was observed at $203 \mathrm{~K}$.
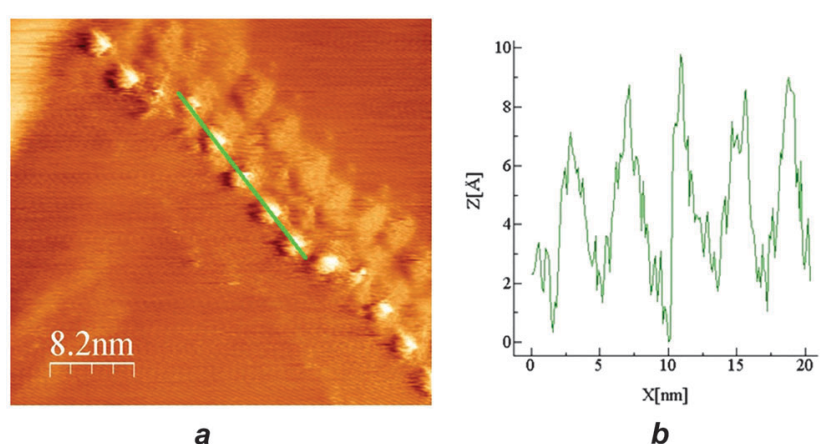

Fig. 1 (a) STM image of a representative chain of beads from $\left[\mathrm{Fe}(\mathrm{bpp})_{2}\right]\left[\mathrm{BF}_{4}\right]_{2}$ drop cast onto HOPG, with widths of $2.5 \mathrm{~nm}$ and heights of $7 \AA$. (b) Profile over the five beads highlighted in (a). 


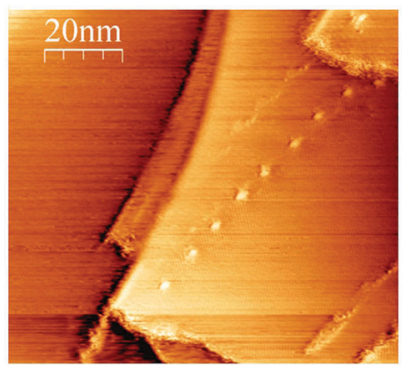

a

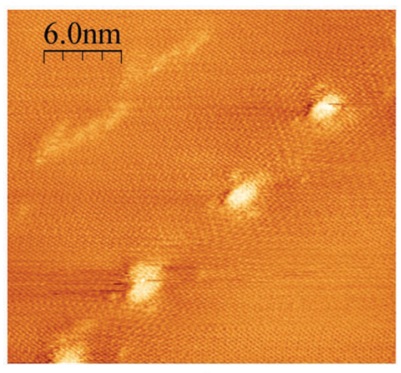

b

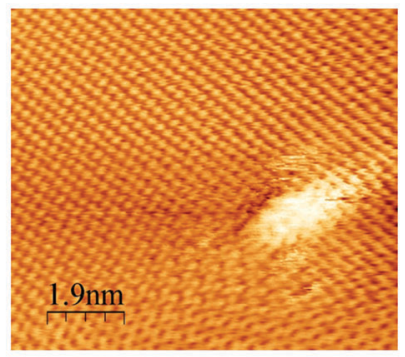

c

Fig. 2 STM images at three different scales of the same set of beads. The underlying graphite lattice can clearly be seen in (c). These beads are comparable in size to those in Fig. 1, but are more widely spaced.

In both the images and the $I / V$ curves, the difference between the types of beads was more pronounced at negative than at positive bias (Fig. 3 and ESI $\dagger$ ).

One interpretation of these data would be that type I and type II beads contain complex molecules in their high-spin and low-spin states. ${ }^{30,38}$ However, since type II beads were observed more frequently in the vicinity of kinks or other discontinuities in the chains (Fig. 3), the conduction properties of the beads may also be influenced by their relationship to their nearest neighbours. Nearly all beads retained the same type I or type II conduction behaviour when the same chain was measured at different biases. However, the "type III" bead in Fig. 3 appears to switch at $203 \mathrm{~K}$, from type I to type II as the bias was decreased in the spectroscopic current maps. This apparent switching is less clear cut in the $I / V$ curves from the same set of beads, however (Fig. 3).
Since the crystallographic dimensions of the $\left[\mathrm{Fe}(\mathrm{bpp})_{2}\right]^{2+}$ cation are $13 \times 13 \times 14 \AA$, with a molecular volume of $c a .620 \AA^{3}$ at $290 \mathrm{~K}$, the beads are too large to correspond to an isolated molecule on the HOPG surface. By volume, the typical bead structure contains $10-50$ molecules of $\left[\mathrm{Fe}(\mathrm{bpp})_{2}\right]^{2+}$ with accompanying anions, assuming the beads contain the intact complex molecule. To address that question, XPS measurements were performed on $\mathrm{nm}$ films of $\left[\mathrm{Fe}(\mathrm{bpp})_{2}\right]\left[\mathrm{BF}_{4}\right]_{2}$, drop-cast from acetone solution onto $\mathrm{Au}(111)$. The resultant photoelectron scan at $293 \mathrm{~K}$ clearly showed the presence of C, N, B, F and Fe (Fig. 4); the Fe: $\mathrm{C}: \mathrm{N}$ composition is $1: 27: 10$, in reasonable agreement with the theoretical values $(1: 22: 10)$, while the $\mathrm{B}: \mathrm{F}$ ratio is $1: 3$ (predicted $1: 4$ ). The $\mathrm{C}$ and $\mathrm{N} 1 \mathrm{~s}$ peaks were both clearly split into multiple components. Binding energies of the fitted carbon peaks at $284.5 \mathrm{eV}, 285.4 \mathrm{eV}$ and $287.1 \mathrm{eV}$ (Fig. 4b) are comparable to those reported for a metal-free bpp derivative, while the two N peaks at $399.7 \mathrm{eV}$ and $401.3 \mathrm{eV}$ (which have an approximate 2:3 ratio, Fig. 4c) can be attributed to the pyrrolic and pyridinic $\mathrm{N}$ atom environments in the bpp ligand, respectively. ${ }^{42}$ Although the conditions of the STM and XPS experiments involve different substrates and film thicknesses, these data provide clear evidence that $\left[\mathrm{Fe}(\mathrm{bpp})_{2}\right]\left[\mathrm{BF}_{4}\right]_{2}$ can retain its structural integrity when drop-cast from acetone.

The Fe $2 \mathrm{p}_{1 / 2}$ and $2 \mathrm{p}_{3 / 2}$ XPS emissions exhibit high-energy satellite peaks, reflecting $3 \mathrm{~d} \rightarrow$ ligand MLCT excitations during the electron emission. ${ }^{27,43}$ The pronounced nature of these satellites is characteristic of the complex being high-spin at the temperature of measurement. ${ }^{44}$ However, cycling the XPS samples about the spin-transition temperature of the compound $\left(T_{1 / 2}=261 \mathrm{~K}\right)$ did not lead to the $1-2 \mathrm{eV}$ reduction in the $2 \mathrm{p}_{3 / 2}$ binding energy, or the weakening of the satellite peaks, that would be characteristic of spin-crossover (ESI $\dagger$ ). While that could reflect decomposition of the compound in the X-ray beam, ${ }^{45}$ an aspect of the chemistry of $\left[\mathrm{Fe}(\mathrm{bpp})_{2}\right]^{2+}$ derivatives that would also explain this observation is discussed below.

With a view to producing SAMs of $\left[\mathrm{Fe}(\mathrm{bpp})_{2}\right]^{2+}$-type centres, $\mathrm{L}^{240}$ was deposited onto gold-coated glass by drop-casting and by SAM formation. XPS data from both types of $\mathrm{L}^{2}$ layers demonstrated the presence of $\mathrm{C}, \mathrm{N}, \mathrm{S}$ and, unexpectedly, a small amount
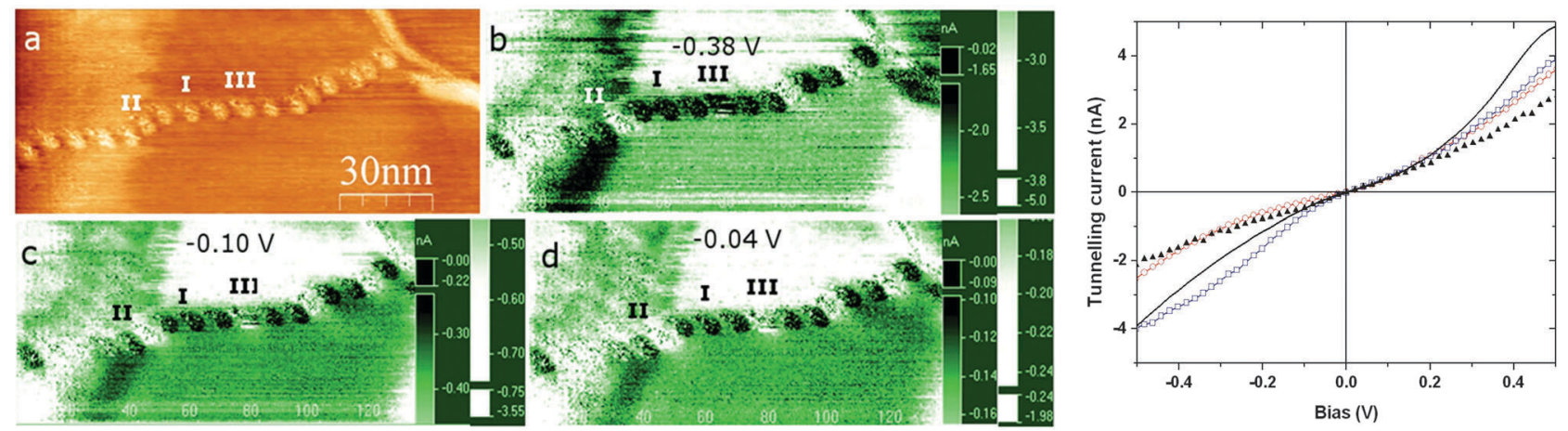

Fig. 3 Left: (a) an STM image taken at $203 \mathrm{~K}$, containing a mixture of type I and type II beads, with corresponding spectroscopic current maps (b) to (d) at different negative biases. Right: $I-V$ curves of the substrate (black line), type I beads (average of ten beads; red circles), type II beads (average of 6 beads; blue squares), and a bead observed to possibly switch at negative bias in the STM images (type III; black triangles). A figure showing the error ranges of these I/V data is in the ESI. $\dagger$ 

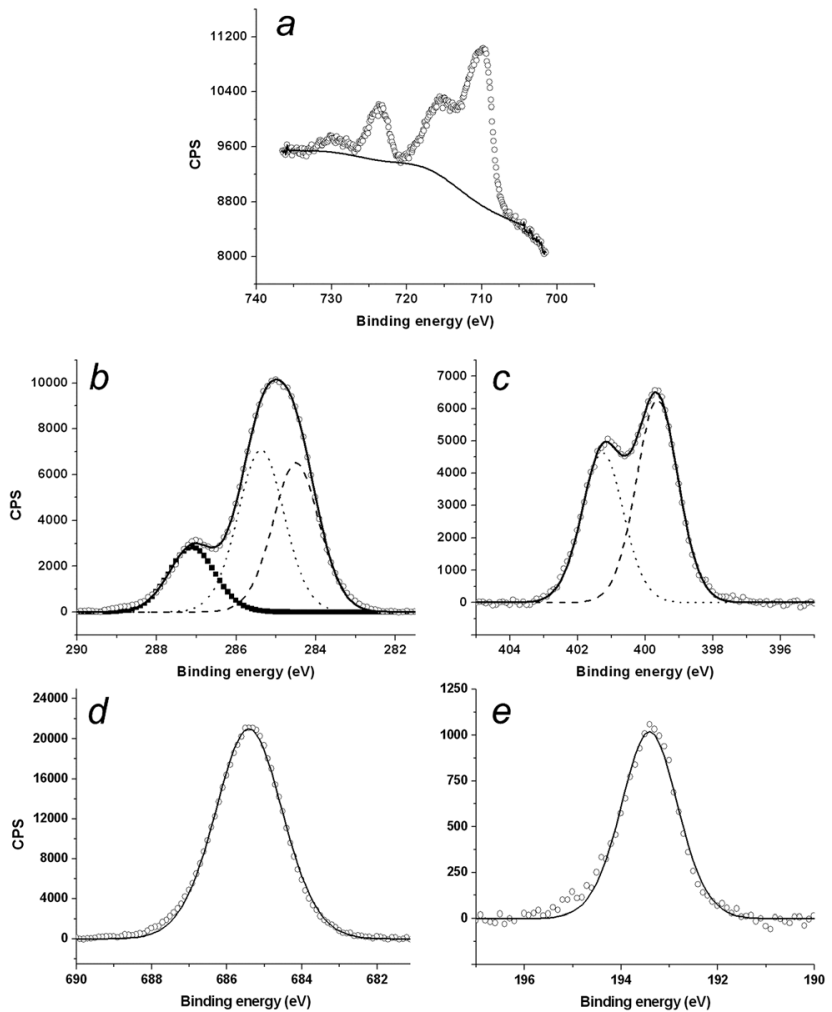

Fig. 4 XPS spectra of (a) Fe $2 p_{1 / 2}$ and $2 p_{3 / 2}$, (b) C 1s, (c) N 1s, (d) F $1 s$ and (e) $\mathrm{B} 1 \mathrm{~s}$, in films of $\left[\mathrm{Fe}(\mathrm{bpp})_{2}\right]\left[\mathrm{BF}_{4}\right]_{2}$ drop-cast onto $\mathrm{Au}(111)$. The carbon region consist of three components, as expected for pyrazole and pyridine, however, the weakest peak is shifted by $1 \mathrm{eV}$ to a higher binding energy than expected. Experimental data are represented by empty circles, while the solid lines correspond to envelopes of fitted components shown in filled squares, dashed and dotted lines.

of O. However, the relative abundance of each element did not match the empirical formula of the ligand, with higher-thanexpected quantities of sulfur compared to the other elements (tabulated in the ESI $\dagger$ ). This discrepancy was more pronounced in the SAMs than in the drop-cast samples, where the $\mathrm{L}^{2}$ layers were thicker and formed more rapidly. The S 2p XPS profiles were more complex than expected, and demonstrated the presence of elemental sulfur as well as bound, unbound and partially oxidised thiol residues, in varying ratios (ESI $\dagger$ ). Similarly, the $\mathrm{N} 1 \mathrm{~s}$ emission demonstrated the presence of the intact bpp moiety in drop-cast films of $\mathrm{L}^{2}$, showing two peaks in a $2: 3$ ratio as before. However, in the SAMs of $\mathrm{L}^{2}$ the ratio of these components was closer to $1: 1$, indicating that the bpp moiety may have fragmented on the surface under these conditions. Finally, the thickness of the deposited layers also varied widely between experiments, at between 3-34 Å by ellipsometry.

We interpret these data as indicating the partial decomposition of $\mathrm{L}^{2}$ at the gold surface by cleavage of the C-S bond, leading to deposition of elemental sulfur. Similar observations have also been made from SAMs derives from 4-mercaptopyridine, which decompose to elemental sulfur on a gold surface over a period of hours in aqueous solution, and more rapidly when dissolved in ethanol. ${ }^{46}$ The precise mechanism behind the instability of $\mathrm{Au} / \mathrm{L}^{2}$ surfaces is unclear, but the $\mathrm{N} 1 \mathrm{~s}$ region indicates that at

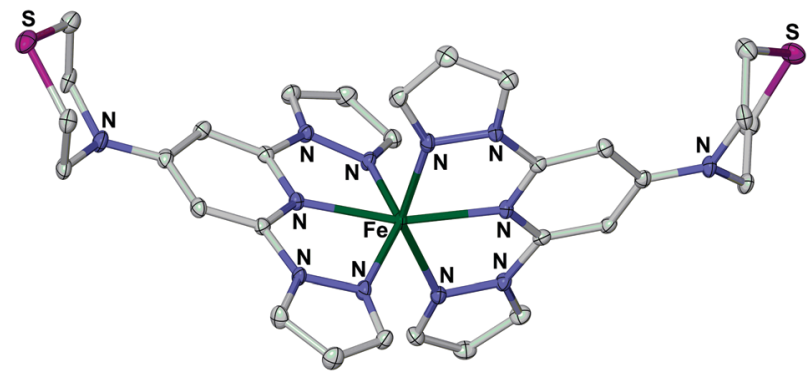

Fig. 5 View of the complex dication in the single crystal $X$-ray structure of $\left[\mathrm{Fe}\left(\mathrm{L}^{3}\right)_{2}\right]\left[\mathrm{BF}_{4}\right]_{2} \cdot \mathrm{H}_{2} \mathrm{O}$. Displacement ellipsoids are at the $50 \%$ probability level, and $\mathrm{H}$ atoms have been omitted for clarity. Experimental details and metric parameters from the crystal structures of three salts of $\left[\mathrm{Fe}\left(\mathrm{L}^{3}\right)_{2}\right]^{2+}$ are in the ESI. $\dagger$

least a significant part of $\mathrm{L}^{2}$ is not intact on the surface, and suggests presence of bpp-derived byproducts from the $\mathrm{C}-\mathrm{S}$ cleavage process.

In the light of these results, the new ligand $\mathrm{L}^{3}$ was prepared, as a derivative of bpp with a remote sulfur-containing tether group that should be more robust on a gold substrate (Fig. 5 and ESI $\dagger$ ). SAMs derived from $\mathrm{L}^{3}$ were indeed more promising, in giving an elemental composition that is close to the formula of the ligand, $\mathrm{C}: \mathrm{N}: \mathrm{S}=17.1: 3.9: 1$ (expected ratio 15:6:1). While SAMs produced from methanol, acetonitrile and chloroform all gave broadly consistent data, the best results were obtained using methanol as solvent. The carbon 1s spectrum shows similar binding energies and fitted component ratios as $\left[\mathrm{Fe}(\mathrm{bpp})_{2}\right]\left[\mathrm{BF}_{4}\right]_{2}$ (ESI $\dagger$ ). The S $2 p$ XPS profile shows two duplets with $2 p_{3 / 2}$ peaks located at $161.9 \mathrm{eV}$ and $163.5 \mathrm{eV}$ (Fig. 6). Although these are commonly assigned to bound and unbound thiol residues, respectively, that does not indicate a poorly formed SAM; both duplets are also characteristic for monolayers of thiane derivatives on gold. ${ }^{47}$ The $\mathrm{N} 1 \mathrm{~s}$ peaks at $401.5 \mathrm{eV}$ and $399.7 \mathrm{eV}$ have an approximate $1: 2$ area ratio that is close to the empirical formula of the ligand (Fig. 6). Ellipsometry data gave consistent thicknesses of 8-9 $\pm 1 \AA$ for different SAMs of $\mathrm{L}^{3}$. While that is shorter than the crystallographic length of the extended $\mathrm{L}^{3}$ molecule ( $c a .13 \AA$ ) , that thickness would be consistent with $20-30 \%$ lower surface coverage than a well-packed alkanethiol SAM, or a binding mode
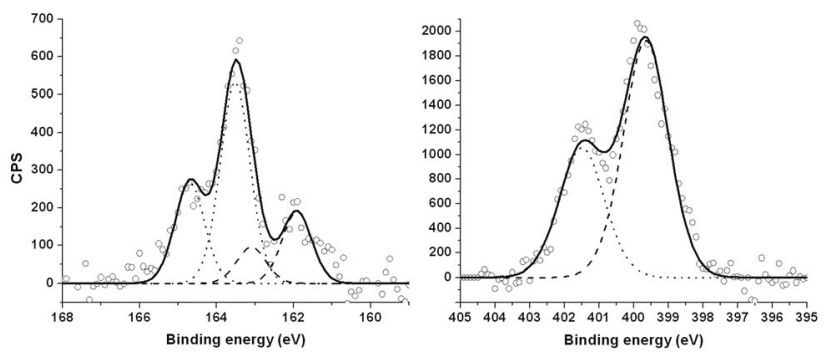

Fig. 6 High-resolution $S 2 p_{3 / 2}$ (left) and $N$ 1s (right) XPS data from SAMs of $L^{3}$, produced from methanol solution. Empty circles represent experimental data, dashed and dotted lines correspond to bound and unbound thiols, respectively, in $\mathrm{S} 2 \mathrm{p}$ region (left) and two distinct environments of nitrogen atoms in $\mathrm{N}$ 1s spectrum (right). Solid lines show envelopes of the fitted peaks. 
where the $\mathrm{L}^{3}$ thiomorpholine group lies flat on the Au surface according to molecular models (ESI $\dagger$ ). For comparison, the thickness of a well-ordered SAM of a different bpp derivative with an alkanethiol tether was measured at $9.7 \AA$, albeit by a different technique. ${ }^{42}$

Incubating SAMs of $\mathrm{L}^{3}$ in acetonitrile solutions of $\mathrm{Fe}\left[\mathrm{ClO}_{4}\right]_{2}$ did not lead to incorporation of iron into the monolayer, according to XPS data which were identical to those from the initial SAM. Similarly, incubating methanol or acetonitrile solutions of the preformed complex $\left[\mathrm{Fe}\left(\mathrm{L}^{3}\right)_{2}\right]\left[\mathrm{ClO}_{4}\right]_{2}$ ( $\mathrm{ESI} \dagger$ ) on gold afforded layers of $\mathrm{L}^{3}$ only, with no iron being present. Evidently, the surface-bound $\mathrm{L}^{3}$ ligand binds iron too weakly to form spin-crossover SAMs, either because of the geometry of the adsorbed ligand or on electronic grounds. Since salts of $\left[\mathrm{Fe}\left(\mathrm{L}^{3}\right)_{2}\right]^{2+}$ are high-spin at room temperature (ESI $\dagger$ ), the iron centres in surface-bound $\mathrm{L}^{3}-\mathrm{Fe}$ complexes should be labile towards ligand displacement reactions which would explain the observed weak interaction between the metal and the SAM.

\section{Conclusions}

We have reproduced the unusual results reported by Grohmann et al., of the formation of "chain of beads" nanostructures upon drop-casting derivatives of $\left[\mathrm{Fe}(\mathrm{bpp})_{2}\right]^{2+}$ (Scheme 1) onto HOPG. ${ }^{30,38}$ Since similar structures are obtained using the parent compound $\left[\mathrm{Fe}(\mathrm{bpp})_{2}\right]\left[\mathrm{BF}_{4}\right]_{2}$, the sulfur-containing substituents in $\left[\mathrm{Fe}\left(\mathrm{L}^{1}\right)_{2}\right]\left[\mathrm{BF}_{4}\right]_{2}$ clearly have no role in formation of the bead structures. Although the composition of the beads could not be probed directly, XPS data from $\left[\mathrm{Fe}(\mathrm{bpp})_{2}\right]\left[\mathrm{BF}_{4}\right]_{2}$ drop-cast onto a gold surface strongly imply that the complex retains its integrity during the drop-casting process. $\neq$ That being the case, the beads (which vary in size between chains) are of appropriate size to contain 10-50 molecules of the compound. Different beads in the same chain exhibit one of two conduction regimes by CITS, which appears to correlate with their proximity to discontinuities in the chain structures. Their different conduction properties might indicate that these beads contain molecules in the high-spin and low-spin states. ${ }^{10,11,38}$ However, with rare exceptions (Fig. 3), no evidence for switching of the beads' conduction properties under increasing bias was observed, that would indicate charge-induced spin-crossover.

The apparent absence of conduction switching in the beads does not invalidate their assignment as high- and low-spin states of the compound. Recent work has indicated that iron(II) complexes which exhibit spin-crossover in the bulk can be either highspin or low-spin on a surface, but may remain trapped in their spin-states under increasing bias or changing temperature in nanostructures below a certain size regime. The threshold size for the recovery of spin-crossover has varied between studies, ${ }^{24,25,28}$ although coverages approaching a full monolayer are required to induce spin-state switching in at least some cases. Hence, the

\$30 nm films of $\left[\mathrm{Fe}(\mathrm{bpp})_{2}\right]\left[\mathrm{BF}_{4}\right]_{2}$ have also been produced by spin-coating acetonitrile solutions of the complex onto a glass substrate. While XPS data were not reported, the spin-state properties of the thin films closely resemble bulk samples of the same compound. ${ }^{10}$ inactivity of $2-6 \mathrm{~nm}$ beads of $\left[\mathrm{Fe}(\mathrm{bpp})_{2}\right]\left[\mathrm{BF}_{4}\right]_{2}$ towards switching under a bias is not unreasonable.

Another factor that could also be relevant to these data, which is unique to the $\left[\mathrm{Fe}(\mathrm{bpp})_{2}\right]^{2+}$ spin-crossover system, is the tendency of the high-spin compounds to adopt an unusual angular Jahn-Teller distortion that inhibits spin-crossover in the solid state. ${ }^{35}$ For example, the three salts of $\left[\mathrm{Fe}\left(\mathrm{L}^{3}\right)_{2}\right]^{2+}$ that we have examined all exhibit this distorted structure by X-ray crystallography, and are not spin-crossover active as a result (Fig. 6 and ESI $\dagger$ ). While $\left[\mathrm{Fe}(\mathrm{bpp})_{2}\right]\left[\mathrm{BF}_{4}\right]_{2}$ does not suffer from this distortion as a bulk material, and thus exhibits spin-crossover, ${ }^{39}$ some other salts of the $\left[\mathrm{Fe}(\mathrm{bpp})_{2}\right]^{2+}$ cation do show it in the crystalline state. ${ }^{48}$ The adoption of the distorted structure by $\left[\mathrm{Fe}(\mathrm{bpp})_{2}\right]^{2+}$ following drop-casting could also contribute to the lack of switching in the bead structures, and to the compound remaining high-spin below $260 \mathrm{~K}$ in the XPS data.

While SAMs of $\mathrm{L}^{3}$ were achieved, attempts to metallate them with iron salts were unsuccessful. This contrasts with closely related derivatives of $\left[\mathrm{Fe}(\text { terpy })_{2}\right]^{2+}\left(\right.$ terpy $=2,2^{\prime}: 6^{\prime}, 2^{\prime \prime}$-terpyridine), which can be assembled into SAMs and other surface nanostructures. ${ }^{49}$ An obvious difference relates to the spin states of the two classes of compounds: $\left[\mathrm{Fe}(\text { terpy })_{2}\right]^{2+}$ derivatives are lowspin and kinetically inert at room temperature, while $\left[\mathrm{Fe}(\mathrm{bpp})_{2}\right]^{2+}$ centres are predominantly high-spin and more reactive towards ligand substitution and solvolysis. We are currently pursuing SAMs based on alternative spin-crossover iron centres, that are less reactive in their high-spin forms and thus more likely to produce switchable surface nanostructures.

\section{Experimental}

The complex $\left[\mathrm{Fe}(\mathrm{bpp})_{2}\right]\left[\mathrm{BF}_{4}\right]_{2}$ was synthesised by the literature method. ${ }^{39}$ The ligand $\mathrm{L}^{2}$ was prepared by a modification of our published procedure, ${ }^{40}$ to avoid contamination by an iodinecontaining byproduct (ESI $\dagger$ ). The synthesis of the new ligand 4-(N-thiomorpholinyl)-2,6-di(pyrazol-1-yl)pyridine $\left(\mathrm{L}^{3}\right)$ and its iron complex salts, and crystal structures and magnetic susceptibility data from the complexes, are also described in the ESI. $\dagger$

Samples of $\left[\mathrm{Fe}(\mathrm{bpp})_{2}\right]\left[\mathrm{BF}_{4}\right]_{2}$ for STM measurements were prepared by drop-casting $10^{-7} \mathrm{M}$ solutions of the complex onto freshly cleaved HOPG. The surface was left to dry before loading into UHV chamber. Gold-coated microscope slides produced by our previously reported procedure ${ }^{50}$ were typically immersed into $1 \mathrm{mM}$ methanol, acetonitrile or chloroform solution of the compounds and left over the night to form SAMs. The samples were removed from the solutions, rinsed with copious amounts of corresponding solvent, dried with a nitrogen stream, rinsed with Milli-Q water, and dried again.

STM measurements were performed with Omicron Variable Temperature UHV STM system at a base pressure of $10^{-9}$ $10^{-11}$ mbar using Pt/Ir $(80: 20)$ tips mechanically cut from $0.25 \mathrm{~mm}$ wire. Tunnelling current was typically set between $0.1 \mathrm{nA}$ and $0.8 \mathrm{nA}$ with applied bias of $0.1 \mathrm{~V}$ to $0.2 \mathrm{~V}$. CITS data was acquired by sweeping voltage between $-0.7 \mathrm{~V}$ and $+0.7 \mathrm{~V}$ at 
every pixel of the topography images. STM data were processed using the Scala Pro and WSxM programs. ${ }^{51}$

High-resolution XPS spectra were acquired with a Thermo Electron Corporation ESCA Lab 250 at $20 \mathrm{eV}$ pass energy with $0.2 \mathrm{eV}$ resolution and processed with CasaXPS software. Binding energies for SAMs were calibrated using the $\mathrm{Au} 4 \mathrm{f}_{7 / 2}$ peak at $83.9 \mathrm{eV}$. However, spectra of the drop-cast films, which showed weak gold signals, were referenced to the $\mathrm{N}$ 1s peak at the lower binding energy of $399.7 \mathrm{eV}$, to maintain consistency across the samples. The $S 2 p$ regions were fitted with duplets of $2 \mathrm{p}_{3 / 2}$ and $2 \mathrm{p}_{1 / 2}$ peaks with a $2: 1$ area ratio, respectively, and separation of $1.18 \mathrm{eV}$ in binding energy.

Temperature readings for the STM measurements were recorded with the thermocouple located in the cooling block, which was coupled to the sample. However, the thermocouple for the XPS measurements was in direct contact with the sample.

The thicknesses of the SAMs was measured with a JobinYvon UVISEL spectroscopic ellipsometer at $70^{\circ}$ angle of incidence and the wavelength was varied between 300 and $800 \mathrm{~nm}$ in $5 \mathrm{~nm}$ steps. Data were modelled and fitted with a simple three-layer system using DeltaPsi2 software. A clean gold substrate was used to obtain values for the base layer, while Cauchy approximation with an assumed refractive index of $n_{\text {inf }}=1.45$ was used to model the SAM layers.

\section{Other measurements}

Elemental microanalyses were performed by the University of Leeds School of Chemistry microanalytical service. Electrospray mass spectra (ESMS) were obtained on a Bruker MicroTOF spectrometer, from MeCN feed solutions. ${ }^{1} \mathrm{H}$ NMR spectra employed a Bruker DPX300 spectrometer, operating at 300.2 MHz. Variable temperature magnetic susceptibility measurements were performed on a Quantum Design SQUID/VSM magnetometer, in an applied field of $5000 \mathrm{G}$. A diamagnetic correction for the sample was estimated from Pascal's constants; ${ }^{52}$ a diamagnetic correction for the sample holder was also measured separately, and applied to the data.

\section{Acknowledgements}

This work was funded by EPSRC grant EP/I014039/1, and by the University of Leeds.

\section{Notes and references}

1 Spin Crossover in Transition Metal Compounds I-III, ed. P. Gütlich and H. A. Goodwin, Top. Curr. Chem., 2004, pp. 233-235.

2 Spin-Crossover Materials - Properties and Applications, ed. M. A. Halcrow, John Wiley \& Sons, Chichester, 2013, p. 568.

3 A. Bousseksou, G. Molnár, L. Salmon and W. Nicolazzi, Chem. Soc. Rev., 2011, 40, 3313.

4 M. A. Halcrow, Chem. Soc. Rev., 2011, 40, 4119.
5 P. Gütlich, Eur. J. Inorg. Chem., 2013, 581; P. Gütlich, A. B. Gaspar and Y. Garcia, Beilstein J. Org. Chem., 2013, 9, 342 .

6 M. A. Halcrow, Polyhedron, 2007, 26, 3523.

7 M. Nihei, T. Shiga, Y. Maeda and H. Oshio, Coord. Chem. Rev., 2007, 251, 2606.

8 S. Hayami, Y. Komatsu, T. Shimizu, H. Kamihata and Y. H. Lee, Coord. Chem. Rev., 2011, 255, 1981.

9 O. Kahn, J. Kröber and C. Jay, Adv. Mater., 1992, 4, 718.

10 M. Matsuda and H. Tajima, Chem. Lett., 2007, 36, 700.

11 A. Rotaru, I. A. Gural'skiy, G. Molnár, L. Salmon, P. Demont and A. Bousseksou, Chem. Commun., 2013, 48, 4163.

12 A. Bousseksou, G. Molnár, P. Demont and J. Menegotto, J. Mater. Chem., 2003, 13, 2069; S. Bonhommeau, T. Guillon, L. M. L. Daku, P. Demont, J. S. Costa, J.-F. Létard, G. Molnár and A. Bousseksou, Angew. Chem., Int. Ed., 2006, 45, 1625.

13 H. J. Shepherd, T. Palamarciuc, P. Rosa, P. Guionneau, G. Molnár, J.-F. Létard and A. Bousseksou, Angew. Chem., Int. Ed., 2012, 51, 3910; H. J. Shepherd, I. A. Gural'skiy, C. M. Quintero, S. Tricard, L. Salmon, G. Molnár and A. Bousseksou, Nat. Commun., 2013, 4, 2607.

14 H. J. Shepherd, G. Molnár, W. Nicolazzi, L. Salmon and A. Bousseksou, Eur. J. Inorg. Chem., 2013, 653; G. Molnár, L. Salmon, W. Nicolazzi, F. Terki and A. Bousseksou, J. Mater. Chem. C, 2014, 2, 1360.

15 M. Cavallini, Phys. Chem. Chem. Phys., 2012, 14, 11867.

16 P. N. Martinho, C. Rajnak and M. Ruben, in Spin-Crossover Materials - Properties and Applications, ed. M. A. Halcrow, John Wiley \& Sons, Chichester, 2013, ch. 14, pp. 375-404.

17 H. Peng, S. Tricard, G. Félix, G. Molnár, W. Nicolazzi, L. Salmon and A. Bousseksou, Angew. Chem., Int. Ed., 2014, 53, 10894.

18 M. C. Muñoz and J. A. Real, Coord. Chem. Rev., 2011, 255, 2068; O. Roubeau, Chem. - Eur. J., 2012, 18, 15230.

19 T. Miyamachi, M. Gruber, V. Davesne, M. Bowen, S. Boukari, L. Joly, F. Scheurer, G. Rogez, T. K. Yamada, P. Ohresser, E. Beaurepaire and W. Wulfhekel, Nat. Commun., 2012, 3, 938.

20 T. G. Gopakumar F. Matino, H. Naggert, A. Bannwarth and F. Tuczek, and R. Berndt, Angew. Chem., Int. Ed., 2012, 51,6262 .

21 H. Naggert, A. Bannwarth, S. Chemnitz, T. von Hofe, E. Quandt and F. Tuczek, Dalton Trans., 2011, 40, 6364.

22 T. G. Gopakumar, M. Bernien, H. Naggert, F. Matino, C. F. Hermanns, A. Bannwarth, S. Mühlenberend, A. Krüger, D. Krüger, F. Nickel, W. Walter, R. Berndt, W. Kuch and F. Tuczek, Chem. - Eur. J., 2013, 19, 15702.

23 T. Palamarciuc, J. C. Oberg, F. El Hallak, C. F. Hirjibehedin, M. Serri, S. Heutz, J.-F. Létard and P. Rosa, J. Mater. Chem., 2012, 22, 9690.

24 B. Warner, J. C. Oberg, T. G. Gill, F. El Hallak, C. F. Hirjibehedin, M. Serri, S. Heutz, M.-A. Arrio, P. Sainctavit, M. Mannini, G. Poneti, R. Sessoli and P. Rosa, J. Phys. Chem. Lett., 2013, 4, 1546.

25 A. Pronschinske, Y. Chen, G. F. Lewis, D. A. Shultz, A. Calzolari, M. Buongiorno Nardelli and D. B. Dougherty, 
Nano Lett., 2013, 13, 1429; A. Pronschinske, R. C. Bruce, G. Lewis, Y. Chen, A. Calzolari, M. Buongiorno-Nardelli, D. A. Shultz, W. You and D. B. Dougherty, Chem. Commun., 2013, 49, 10446.

26 S. Shi, G. Schmerber, J. Arabski, J.-B. Beaufrand, D. J. Kim, S. Boukari, M. Bowen, N. T. Kemp, N. Viart, G. Rogez, E. Beaurepaire, H. Aubriet, J. Petersen, C. Becker and D. Ruch, Appl. Phys. Lett., 2009, 95, 043303.

27 T. Mahfoud, G. Molnár, S. Cobo, L. Salmon, C. Thibault, C. Vieu, P. Demont and A. Bousseksou, Appl. Phys. Lett., 2011, 99, 053307.

28 M. Bernien, D. Wiedemann, C. F. Hermanns, A. Krüger, D. Rolf, W. Kroener, P. Müller, A. Grohmann and W. Kuch, J. Phys. Chem. Lett., 2012, 3, 3431.

29 A. D Naik, M. M. Dîrtu and Y. Garcia, J. Phys.: Conf. Ser., 2010, 217, 012032.

30 M. S. Alam, M. Stocker, K. Gieb, P. Müller, M. Haryono, K. Student and A. Grohmann, Angew. Chem., Int. Ed., 2010, 49, 1159.

31 M. Cavallini, I. Bergenti, S. Milita, J. C. Kengne, D. Gentili, G. Ruani, I. Salitros, V. Meded and M. Ruben, Langmuir, 2011, 27, 4076.

32 M. Cavallini, I. Bergenti, S. Milita, G. Ruani, I. Salitros, Z.-R. Qu, R. Chandrasekar and M. Ruben, Angew. Chem., Int. Ed., 2008, 47, 8596.

33 S. Basak, P. Hui and R. Chandrasekar, Chem. Mater., 2013, 25, 3408.

34 S. Bin-Salamon, S. Brewer, S. Franzen, D. L. Feldheim, S. Lappi and D. A. Shultz, J. Am. Chem. Soc., 2005, 127, 5328; G. Poneti, L. Poggini, M. M. B. Cortigiani, L. Sorace, E. Otero, P. Sainctavit, A. Magnani, R. Sessoli and A. Dei, Chem. Sci., 2015, 6, 2268.

35 M. A. Halcrow, Coord. Chem. Rev., 2009, 253, 2493; L. J. Kershaw Cook, R. Mohammed, G. Sherborne, T. D. Roberts, S. Alvarez and M. A. Halcrow, Coord. Chem. Rev., 2015, 289-290, 2.

36 M. A. Halcrow, New J. Chem., 2014, 38, 1868.

37 D. Secker, S. Wagner, S. Ballmann, R. Härtle, M. Thoss and H. B. Weber, Phys. Rev. Lett., 2011, 106, 136807; V. Meded, A. Bagrets, K. Fink, R. Chandrasekar, M. Ruben, F. Evers,
A. Bernand-Mantel, J. S. Seldenthuis, A. Beukman and H. S. J. van der Zant, Phys. Rev. B: Condens. Matter Mater. Phys., 2011, 83, 245415.

38 A. Grohmann, M. Haryono, K. Student, P. Müller and M. Stocker, Eur. J. Inorg. Chem., 2013, 662.

39 J. M. Holland, J. A. McAllister, Z. Lu, C. A. Kilner, M. ThorntonPett and M. A. Halcrow, Chem. Commun., 2001, 577.

40 L. J. Kershaw Cook, J. Fisher, L. P. Harding and M. A. Halcrow, Dalton Trans., 2015, 44, 9417.

41 C. Liu, H. Chang and A. J. Bard, Langmuir, 1991, 7, 1138; T. M. Bernhardt, B. Kaiser and K. Rademann, Surf. Sci., 1998, 408, 86.

42 C. Shen, M. Haryono, A. Grohmann, M. Buck, T. Weidner, N. Ballav and M. Zharnikov, Langmuir, 2008, 24, 12883.

43 S. G. Chiuzbaian, M. Neumann, O. Waldmann, B. Schneider, I. Bernt and R. W. Saalfrank, Surf. Sci., 2001, 482-485, 1272; T. Yamashita and P. Hayes, Appl. Surf. Sci., 2008, 254, 2441. 44 L. N. Mazalov, I. P. Asanov and V. A. Varnek, J. Electron Spectrosc. Relat. Phenom., 1998, 96, 209.

45 M. S. Lazarus, M. A. Hoselton and T. S. Chou, Inorg. Chem., 1977, 16, 2549.

46 E. A. Ramírez, E. Cortés, A. A. Rubert, P. Carro, G. Benítez, M. E. Vela and R. C. Salvarezza, Langmuir, 2012, 28, 6839.

47 M. C. Lennartz, M. Baumert, S. Karthäuser, M. Albrecht and R. Waser, Langmuir, 2011, 27, 10312.

48 J. M. Holland, J. A. McAllister, C. A. Kilner, M. ThorntonPett, A. J. Bridgeman and M. Halcrow, J. Chem. Soc., Dalton Trans., 2002, 548; J. Elhaïk, D. J. Evans, C. A. Kilner and M. A. Halcrow, Dalton Trans., 2005, 1693; J. Elhaïk, C. A. Kilner and M. A. Halcrow, Dalton Trans., 2006, 823.

49 S. Liatard, J. Chauvin, D. Jouvenot, F. Loiseau and A. Deronzier, J. Phys. Chem. C, 2013, 117, 20431; R. Sakamoto, K.-H. Wu, R. Matsuoka, H. Maeda and H. Nishihara, Chem. Soc. Rev., 2015, DOI: 10.1039/c5cs00081e.

50 Z. H. Al-Lawati, R. J. Bushby and S. D. Evans, J. Phys. Chem. C, 2013, 117, 7533.

51 I. Horcas, R. Fernandez, J. M. Gomez-Rodriguez, J. Colchero, J. Gomez-Herrero and A. M. Baro, Rev. Sci. Instrum., 2007, 78, 013705.

52 C. J. O’Connor, Prog. Inorg. Chem., 1982, 29, 203. 